\section{Investigate smog to inform policy}

The severe air-pollution episodes that affected Europe this spring (see, for example, go.nature. $\mathrm{com} / \mathrm{si6mhu}$ and go.nature. com/1b7ygf) highlight the need for effective policy measures and management strategies, given the persistence and potential global reach of such acute events.

Reducing particulate matter, ozone and greenhouse gases is essential to mitigate air pollution as well as climate change, so policies need to be coordinated. For example, climate policy encourages use of fuels such as diesel (because its combustion releases less carbon dioxide per kilometre than petrol) and biomass, which offsets most of its own carbon release as it grows. However, both fuels generate harmful particulates.

For now, the factors that triggered Europe's latest air-pollution episodes and influenced their duration and spread must be investigated. This insight will aid the development of much-needed cross-border policies that are based on sound scientific advice.

Paul S. Monks ${ }^{\star}$ University of

Leicester, UK.

psm7@leicester.ac.uk

${ }^{*}$ On behalf of 11 co-authors (see go.nature.com/nxe3pb for full list).

\section{Soil observatory lets researchers dig deep}

The UK Soil Observatory (UKSO) launched last month in London. It provides a global web-based platform for the acquisition and dissemination of soil data (www.ukso.org).

Soil security is rising rapidly on government agendas, driven by the United Nations Global Soil Partnership (see Nature 492, 186; 2012). Researchers therefore need to be able to predict how soils will respond to changing climate, vegetation, erosion and pollution (M. W. Schmidt et al. Nature 478, 49-56; 2011).
The UKSO is a step change in meeting this challenge.

Expanding on the success of the mySoil crowd-sourcing app (see W. Shelley et al. Nature 496, 300; 2013), the UKSO is a community initiative funded by the Natural Environment Research Council. It offers live data streaming and pioneers a route to big data resources. It is comprehensively linked to other sources of soil data, both free and commercial, and to real-time data from the COSMOS national soilmoisture network.

The UKSO interactive map viewer provides access to a huge range of information, from local soil biodiversity to metal concentrations in topsoil.

Data from the UKSO will underpin major government projects, such as the $\mathfrak{£} 160$-million (US\$268-million) strategy for agricultural technologies (go.nature.com/6oqmxh), and will catalyse associated industrial and commercial enterprises.

Russell Lawley NERC/British Geological Survey, Environmental Science Centre, Nottingham, UK. Bridget A. Emmett, David A. Robinson NERC Centre for Ecology and Hydrology, Environment Centre Wales, Bangor, UK.

davi2@ceh.ac.uk

\section{Strict vaccine quality control in China}

We disagree that vaccine quality control is a problem in China

(Nature 507, S12-S13; 2014). In

2013, for example, the agency responsible for the country's vaccine quality control - the National Institutes for Food and Drug Control (NIFDC) in Beijing - was designated as a World Health Organization Collaboration Center for Standardization and Evaluation of Biologicals.

Since 2002, China has implemented batch release of vaccines as a key quality-control measure to ensure that they are safe to use. Each batch is screened by the NIFDC before its release. China produces about 4,000 batches of vaccines annually, corresponding to some 700 million doses.

In 2011, eleven batches of vaccine were rejected because they were of sub-standard quality; three were rejected in 2012 and four in 2013.

Together, these represent a total of 1 million doses and correspond to just $0.05 \%$ of throughput over three years - a mark of China's stringent vaccine-production processes and of the success of batchtesting practices.

Zhenglun Liang, Qunying Mao, Junzhi Wang National Institutes for Food and Drug Control, Beijing, China. wangjz@nifdc.org.cn

\section{Rethink Campania's toxic-waste scandal}

As you point out, it is not easy to prove a correlation between the health issues of people in Italy's Campania region and their exposure to toxic waste (see Nature 508, 431; 2014). The authorities seem to prefer to blame lifestyle factors, but that does not explain why thousands of non-smoking and sober sheep in the area have had to be removed from the food chain.

This waste crisis is a result of certified disposals as well as of illegal dumping, currently being investigated by the European Union project ENTITLE (www.politicalecology.eu); the crisis has been associated with environmental injustice and a disregard for democracy (see G. D’Alisa et al. Ecol. Econ. 70, 239-249; 2010). The area has become a political laboratory for testing extreme regulations. It is in a permanent state of emergency, with environmental and civil-rights laws suspended.

Rather than abusing emergency decrees in this way, a different type of laboratory is needed, in which social and natural scientists can accumulate the facts necessary to address the injustices embodied in the current patterns of contamination and exposure.

Giacomo D'Alisa Autonomous University of Barcelona, Spain. Marco Armiero Royal Institute of Technology, Stockholm, Sweden. Salvatore Paolo De Rosa Lund University, Sweden. giacomo_dalisa@yahoo.it

\section{Internal factors drive Chinese patent surge}

China is outpacing many countries in patenting renewableenergy technologies (see J.E. Trancik Nature 507, 300-302; 2014). But this achievement has arguably been inflated by the country's patenting laws.

For example, according to the Espacenet patent database, from 1978 to 2008 China was awarded 21,192 patents on solar photovoltaics. Of these, $99 \%$ were granted by China's State Intellectual Property Office. By contrast, the US Patent and Trademark Office granted just 83 patents in this field over the same period (C.-Y. Wu Scientometrics 98, 429-446; 2014).

The overwhelmingly domestic focus of China's patenting activity is a result of its patent-law system, which is designed to promote indigenous innovations. Chinese firms tend to file as many patents as possible for a single equivalent invention, encouraged by extra public subsidies and administrative support (see, for example, A. de la Tour et al. Energy Policy 39, 761-770; 2011).

This factor needs to be borne in mind when evaluating Chinese patent figures for the purposes of technological ranking. Ching-Yan Wu Fu Jen Catholic University, Taiwan.

Mei-Chih Hu National Tsing Hua University, Taiwan.

John A. Mathews Macquarie University, Sydney, Australia. mchu@mx.nthu.edu.tw 